
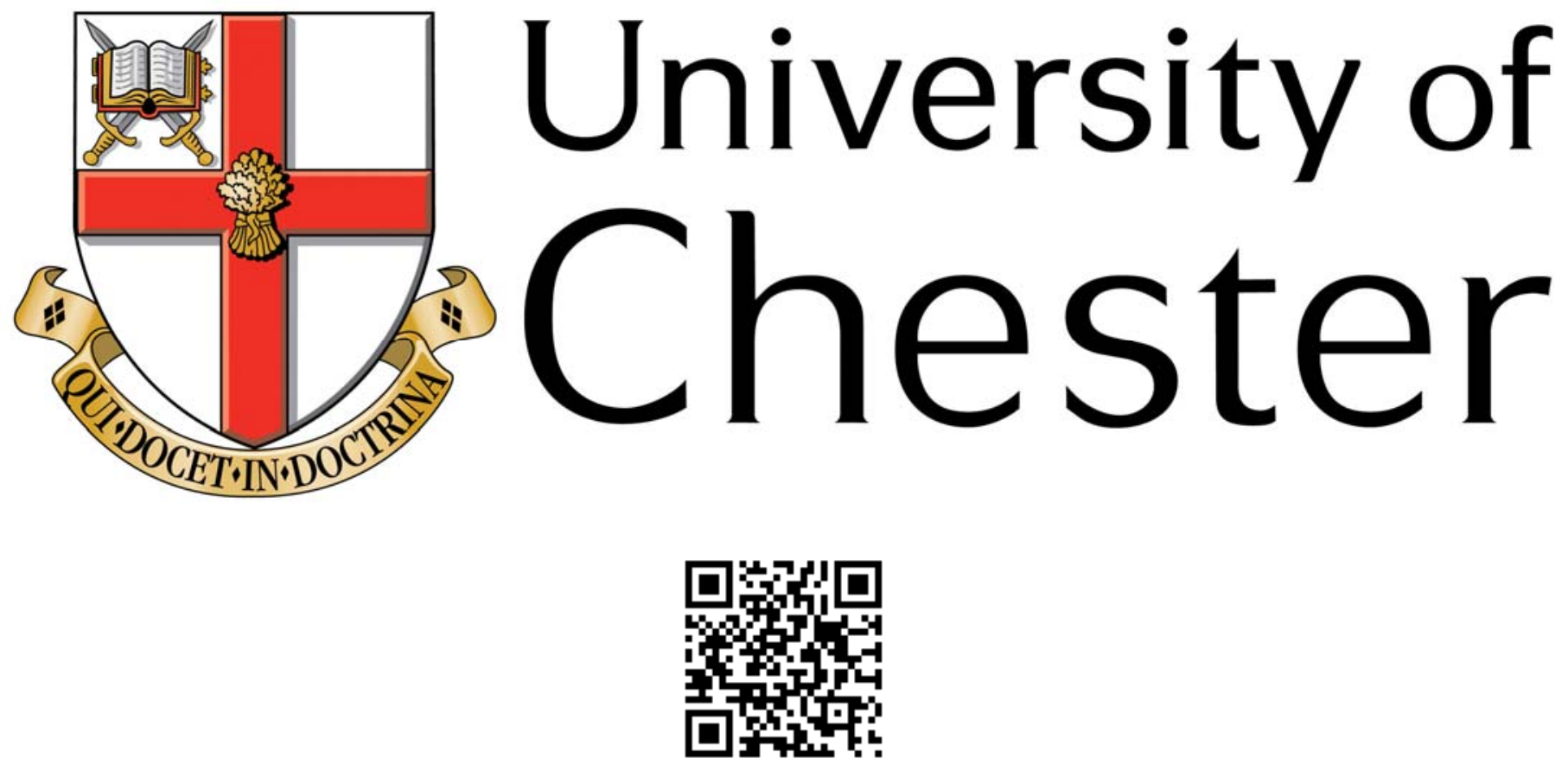

This work has been submitted to ChesterRep - the University of Chester's online research repository

\title{
http://chesterrep.openrepository.com
}

Author(s): David G Reid ; Graham C Smith

Title: The X-ray photoelectron spectroscopy of surface films formed during the ASTM D-130/ISO 2160 copper corrosion test

Date: 2014

Originally published in: Petroleum Science and Technology

Example citation: Reid, D.G., \& Smith, G.C. (2014). The X-ray photoelectron spectroscopy of surface films formed during the ASTM D-130/ISO 2160 copper corrosion test. Petroleum Science and Technology, 32(4), 387-394

Version of item: Authors' post-print (author accepted manuscript)

Available at: http://hdl.handle.net/10034/315462 


\section{X-ray Photoelectron Spectroscopy of Surface Films formed during the ASTM D-130 / ISO 2160 Copper Corrosion Test}

For submission to Petroleum Science and Technology

David G. Reid and Graham C. Smith*

Shell Global Solutions UK

Shell Technology Centre Thornton

PO Box 1

Chester

$\mathrm{CH} 13 \mathrm{SH}$

UK

*Author for correspondence:

Tel +441513735611

Fax +44 1513735220

e-mail: graham.c.smith@shell.com

Present address

Department of Natural Sciences,

Faculty of Science and Engineering,

University of Chester,

Parkgate Road,

Chester,

CH1 4BJ,

UK.

Tel: +44 1244513922

e-mail: graham.smith@chester.ac.uk

Running head: XPS of surface films formed in $\mathrm{Cu}$ corrosion tests

\section{Abstract}

The surface chemistry of ISO 2160 copper strips tested in iso-octane with elemental sulphur, aliphatic, cyclic and aromatic thiols, diphenyl sulphide and diphenyl disulphide individually 
or in combination was studied using XPS. Aliphatic thiols bonded through the sulphur whereas elemental sulphur formed a cuprous sulphide layer. Aromatics bonded partially through the sulphur with the rings oriented horizontally due to $\pi$ orbital interactions, accounting in part for their inhibitory effects in the test. The test rating was not directly related to the sulphur concentration in solution or on the surface, and certain combinations of species resulted in higher levels of sulphur at the surface than found individually. 


\section{Introduction}

The ASTM D130 copper strip test, principally equivalent to both the IP 154/2000 test and the ISO 2160:1998 test (European Committee for Standardization,1998) is the industry standard for testing petroleum products' corrosiveness to copper. This standard is intended to identify and prevent the release of petroleum products corrosive to vehicle engines and distribution system components. The basis of the test is immersion of a prepared copper strip in a test solution for a specified time and temperature with subsequent rating against a standard. The corrosion rating descriptions are given in Table 1 , with generally a rating of 1 (either 1a or $1 \mathrm{~b}$ ) accepted as a pass. However, the scope of the test does not include identification of the causes of test failures (Kashima and Nose, 1959), a lack of clear understanding of which can increase the difficulty and time taken in tackling issues that may occasionally arise associated with the corrosiveness of petroleum products.

Sulfur species are thought to be the underlying cause of copper strip corrosion test failures. Elemental sulfur alone can cause corrosion at just a few parts per million, but the exact concentration required for copper strip test failure depends upon the matrix of the test fuel (Garcia-Anton et.al., 1990). At low concentrations, thiols can inhibit the reaction between elemental sulfur and copper, whereas at higher concentrations with elemental sulfur they may increase corrosion (Garcia-Anton et.al., 1995). Thiols with longer carbon chains produce less of a synergistic effect, although self-assembled monolayers of dodecanethiol can give corrosion protection on copper surfaces (Feng et.al., 1997). Aromatic thiols are more reactive to copper than aliphatic thiols, causing increased inhibition of corrosion by elemental sulfur. Hydrogen sulfide alone can cause failure in the copper strip corrosion test even when present at very low concentrations. Hydrogen sulfide also has a strong synergistic effect with elemental sulfur, increasing copper corrosion. Work carried out on the corrosion testing of 
liquefied petroleum gas showed that hydrogen sulfide causes copper corrosion at lower concentrations than elemental sulfur does (Clarke and Lesage, 2006).

Scanning electron microscopy with energy-dispersive X-ray analysis (SEM-EDX) has been used to investigate surface concentrations of sulfur after testing according to ASTM D130 (Garcia-Anton et.al., 1990, 1995), and Schreifels et al. (1989, 1991) used Auger electron spectroscopy (AES) to construct models of the surface films formed on copper during the test. The use of X-ray photoelectron spectroscopy (XPS) for the examination of copper strip corrosion test pieces has not been reported, although it has greater surface sensitivity than SEM-EDX and provides more information about chemical states than AES. However, the method has been used to construct models for complexes formed by copper and corrosion inhibitors (Vastang et.al., 2001; Ye et.al., 1998; Al Kharafi et.al., 2007). Here, we use XPS to provide surface composition and chemistry information on copper strips after testing sulfur species in iso-octane as functions of concentration and molecular structure, individually and in combination.

\section{Experimental}

Ethanethiol, 1-propanethiol, 1-butanethiol, 1-hexanethiol, cyclohexane thiol, thiophenol, diethyl sulfide, diethyl disulfide, diphenyl sulfide, diphenyl disulfide and elemental sulfur were obtained from Sigma-Aldrich. 'AnalaR Normapur' (analytical grade) 2,2,4trimethylpentane (iso-octane) was obtained from VWR International. Microcoulometry using a Thermo Euroglas ECS 1200 determined the sulfur content of the iso-octane to be less than $0.2 \mathrm{mg} / \mathrm{kg}$ (the detection limit of the apparatus).

Test solutions were prepared by blending a sulfur species into iso-octane. For sulfur species that were solid at room temperature, the solutions were mixed for approximately thirty minutes with an ultrasonic probe before being filtered to remove any remaining solids. The 
sulfur concentrations of the solutions were then verified by WD-XRF using a PANalytical Axios instrument with a $4 \mathrm{~kW}$ rhodium X-ray tube with elemental sulfur in white oil as a calibration standard. Solutions were diluted down to the desired concentrations in several stages, verifying the sulfur concentrations at each stage by WD-XRF. Solutions were prepared as and when needed, reducing the time in which volatile species could be lost from solution.

The copper test strips (Stanhope-Seta) were polished in two stages in accordance with the ISO 2160:1998 (equivalent to ASTM D130) standard procedure (European Committee for Standardization, 1998). The strips were placed in test tubes containing the test solutions, which were then maintained in a temperature-controlled water bath at $50^{\circ} \mathrm{C}$ for three hours. The strips were then rinsed in iso-octane, rated in accordance with the standard, photographed and introduced into the fast-entry airlock of the ultra-high vacuum XPS instrument. Note that although great care was taken and all ratings were by one of the authors only (DGR), there are some apparent inconsistencies in the tables of results. This variation is believed to reflect the sensitivity of the test, even when carried out under optimal conditions. Consequently no posttest rating revisions have been made to the data presented here, and the results are asdetermined at the time of measurement, with no consolidation, cross-referencing or homogenisation.

The XPS spectra reported in this study were acquired using two instrument configurations. The first used a VG Microtech $100 \mathrm{~mm}$ mean radius analyser with triple-channeltron detection and selectable slits, with a twin anode $\mathrm{Mg} / \mathrm{Al} \mathrm{X}$-ray source. Depth profiling was conducted using an argon ion beam of $3.5 \mathrm{kV}$ energy from a VG Microtech EX05 ion gun. The second used a more sensitive analyser (Specs $\mathrm{GmbH} 150 \mathrm{~mm}$ mean radius analyser with 9channeltron detection) and a monochromated $\mathrm{Al} \mathrm{K \alpha} / \mathrm{Ag} \mathrm{L} \alpha$ X-ray source. Several of the analyses were repeated on both instrument configurations. The high-resolution scans over 
individual photoelectron lines reported here were generally acquired using the more sensitive analyser and the monochromated $\mathrm{Al} \mathrm{K} \alpha$ source.

XPS survey scans were carried out on all samples and high resolution scans were obtained from the $\mathrm{C} 1 \mathrm{~s}, \mathrm{O} 1 \mathrm{~s}, \mathrm{Cu} 2 \mathrm{p}$ and, where appropriate, $\mathrm{S} 2 \mathrm{p}$ and $\mathrm{Cu}$ LMM X-ray excited Auger peaks. Data were quantified using Scofield photoelectron cross sections (Scofield, 1976) corrected for the energy dependence of the analyser transmission and the energy dependence of the electron mean free paths. The XPS technique is sensitive to all elements except $\mathrm{H}$ and $\mathrm{He}$, and the standard quantification algorithm provides results normalized to $100 \%$ assuming the composition is constant over the information depth (typically $5-10 \mathrm{~nm}$ maximum).

\section{Results and Discussion}

\subsection{Copper}

Prior to any copper strip corrosion testing, copper test strips were characterized as-received, after polishing according to the ASTM-D130 procedure, and after testing in pure iso-octane. These measurements formed a base-line from which changes as a result of testing in model blends could be assessed. A summary of the surface compositions from these specimens is given in Table 2. The fresh as-received surface was relatively clean, by conventional standards. Note that due to the surface sensitivity of the technique, the value of $46.8 \%$ carbon reported in the Table corresponds to a hydrocarbon contamination layer of $\sim 2 \mathrm{~nm}$, and is typical of untreated metal surfaces exposed to the laboratory environment. A significantly more contaminated surface would be expected for a sample exposed to the laboratory environment for an extended time. The contaminant levels were reduced by polishing, with no significant increase in the carbon signal seen after testing in iso-octane. Oxygen levels were reduced by polishing, indicating removal of the surface oxide on the copper test strip, and in agreement with this the level of copper in the spectrum increased significantly. The 
oxygen level returned to approximately its as-received value after testing the polished strip in pure iso-octane, but the copper signal remained above its initial level. These results indicate a small increase in surface oxidation of the strip during the test, possibly as a result of dissolved air in the iso-octane. The low levels of other surface contaminants found on the as-received surface were removed by polishing and did not re-appear. In particular, no sulfur was found after testing in pure iso-octane.

High resolution scans were made over the $\mathrm{C} 1 \mathrm{~s}, \mathrm{Cu} 2 \mathrm{p}$ and $\mathrm{O} 1 \mathrm{~s}$ lines, and the data curvefitted with established chemical state models to provide a full characterisation of the surfaces. The results for the polished and tested surfaces are shown in Figures 1 and 2 respectively. The $\mathrm{Cu} 2 \mathrm{p}_{3 / 2}$ peak from the as-received surface showed a strong component at $\sim 932.5 \mathrm{eV}$ typical of metallic or $\mathrm{Cu}(\mathrm{I})$ species. It also showed a component at $\sim 934.6 \mathrm{eV}$ and shake-up peaks in the region of $938-948 \mathrm{eV}$, both of which are indicative of $\mathrm{Cu}(\mathrm{II})$ species. The $\mathrm{Cu} \mathrm{X}$-ray excited LMM Auger peak in the survey spectrum was found at an energy also indicative primarily of $\mathrm{Cu}(\mathrm{II})$ species. The $\mathrm{C} 1 \mathrm{~s}$ peak showed a strong main component at $\sim 285.0 \mathrm{eV}$ due to $\mathrm{C}-\mathrm{C}$ bonding in hydrocarbons, with a number of minor components on the high binding energy side attributed to increasing degrees of oxygen bonding. The carbon-oxygen bonding species were reflected in the $\mathrm{O} 1 \mathrm{~s}$ peak, although the $\mathrm{COO}^{-}$component is not expected to be separately-resolved from $\mathrm{C}-\mathrm{O}$ and $\mathrm{C}=\mathrm{O}$ in this case. The $\mathrm{O} 1 \mathrm{~s}$ peak also showed a relatively broad component at $\sim 530.7 \mathrm{eV}$. This contained a number of unresolved contributions from species such as $\mathrm{Cu}(\mathrm{OH})_{2}, \mathrm{Cu}_{2} \mathrm{O}$ and/or $\mathrm{CuO}$.

On polishing (Figure 1) the copper peak was reduced to almost a single component at 932.7 $\mathrm{eV}$, with a narrow line and weak shake-up characteristic of primarily metallic copper with only a very weak contribution from $\mathrm{Cu}_{2} \mathrm{O}$ at $\sim 934.6 \mathrm{eV}$. The $\mathrm{Cu}$ X-ray excited LMM Auger peak in the survey spectrum was found at an energy also indicative primarily of metallic $\mathrm{Cu}^{0}$ species. The $\mathrm{C} 1 \mathrm{~s}$ peak showed a strong main component at $\sim 285.0 \mathrm{eV}$ due to $\mathrm{C}$-C bonding 
in hydrocarbons, with a number of minor components on the high binding energy side attributed to increasing degrees of oxygen bonding. The oxygen signal showed a broad feature resolvable into $\mathrm{O}-\mathrm{C}$ and $\mathrm{O}=\mathrm{C}$ bonded components, reflecting the information in the $\mathrm{C} 1 \mathrm{~s}$ peak, and a sharp and well-resolved contribution at $\sim 530.4 \mathrm{eV}$ due to $\mathrm{Cu}_{2} \mathrm{O}$.

After testing for three hours in pure iso-octane at $50^{\circ} \mathrm{C}$ (Figure 2), the $\mathrm{Cu} 2 \mathrm{p}_{3 / 2}$ peak showed evidence for a weak $\mathrm{Cu}$ (II) component, the LMM Auger peak in the survey spectrum had shifted slightly to an energy consistent with metallic and $\mathrm{Cu}(\mathrm{I})$ species, the oxygen peak was little changed in overall form, and the $\mathrm{C} 1 \mathrm{~s}$ peak showed a relative reduction in the proportion of $\mathrm{C}-\mathrm{O}$ and $\mathrm{C}=\mathrm{O}$ groups and a relative increase in $\mathrm{C}-\mathrm{C}$ and $\mathrm{COO}^{-}$bonding.

Using readily-available electron inelastic mean free path data (Tanuma et.al., 1993), and assuming the presence of a uniform hydrocarbon contamination layer over a uniform oxide layer on the metal surface, that data are consistent with a hydrocarbon overlayer of $\sim 2 \mathrm{~nm}$ thickness over a mixed copper oxide/hydroxide layer $\sim 1 \mathrm{~nm}$ thick over the metallic copper. Testing in pure iso-octane appeared to result in the growth of a very thin layer (average $\sim 0.1$ $\mathrm{nm}$ ) of $\mathrm{CuO}$ over the $\mathrm{Cu}_{2} \mathrm{O}$, with a small increase in the average thickness of the hydrocarbon layer. In reality, the surface is rough and any overlayers present will be of variable thickness and variable coverage. Nevertheless, this simple model forms a useful starting point for interpretation of data from subsequent tests.

\subsection{Individual Sulfur Species at $20 \mathrm{mg} / \mathrm{l}[\mathrm{S}]$}

All sulfur species were individually blended with iso-octane at approximately $20 \mathrm{mg} \mathrm{S} / \mathrm{l}$ and tested for corrosiveness in the ASTM D130 test, before being analyzed by XPS. Table 3 shows the results of the ratings, the surface compositions and the binding energies of the sulfur $2 \mathrm{p}_{3 / 2}$ photoelectron peaks. 
From Table 3, only elemental sulfur was able to cause a test failure (any rating higher than a ' $1 b$ ') in this series of experiments. Note that the concentration of sulfur at the surface of the copper strip tested in iso-octane and elemental sulfur was $3.7 \%$, and this level resulted in test failure. However, the test in iso-octane and ethanethiol gave a much higher sulfur concentration on the strip of $18.4 \%$, yet a test pass with a rating of ' $1 \mathrm{~b}$ ' was recorded. Furthermore, 1-propanethiol and iso-octane together yielded a strip that showed $13.8 \%$ sulfur at the surface, with a rating of only ' $1 \mathrm{a}$ ', the lowest available. These results demonstrate that the corrosion ratings are not proportional to the concentration of sulfur at the surface of the test strip or to the concentration of sulfur in the solution. The ratings very much depend upon the type of sulfur species present. Further, the concentration of sulfur measured on the surface depends strongly on the molecular form, for the same nominal concentration of sulfur in the liquid.

The solutions containing thiols produced test strips that were low in oxygen at the surface, but high in carbon and sulfur. This was most likely due to copper thiolates rather than copper oxides being the major species at the surface of the copper strips.

Table 3 also shows the binding energies of the sulfur $2 p_{3 / 2}$ photoelectron peaks. These cover a relatively narrow range from $162.23 \mathrm{eV}$ when elemental sulfur was blended with the isooctane, through to $162.82 \mathrm{eV}$ when thiophenol was used. An average value from the literature for $\mathrm{Cu}-\mathrm{S}$ bonds is $162.0 \mathrm{eV}$, in reasonable agreement with the measured value for elemental sulfur on the surface. However, carbon-sulfur bonds in organics are typically found at higher binding energies in the range $163.1 \mathrm{eV}$ (e.g. thiophenol) up to $164.4 \mathrm{eV}$ (diphenyl disulfide). The lower values determined here are indicative of the sulfur being in intermediate chargetransfer states between organic and metallic bonding. This is consistent with bonding of the organic species to the copper surface through the sulfur, as expected from studies of selforganizing thiol films on evaporated and polycrystalline copper metal surfaces (Bain et.al, 
1989, Sung et.al., 2000) and from model studies on $\mathrm{Cu}(111)$ and $\mathrm{Cu}(100)$ crystalline surfaces using density functional theory (Ferral et.al., 2006).

Figure 3 shows the trend in the XPS results from strips tested in straight-chain thiols with isooctane at $20 \mathrm{mg} / \mathrm{l}$ sulfur, with all except the ethanethiol giving a '1a' pass rating. Overall, sulfur concentration at the surface of the copper strips decreased as carbon chain length increased. Taking into account the slight attenuation of the sulfur signal by the hydrocarbon chains, it appears that a thiol's hydrocarbon chain length affects its ability to react with a copper test strip within the duration of the corrosion test. The increase in copper and oxygen with increased hydrocarbon chain length indicates that thiols with longer hydrocarbon chains do not bond to the copper surface as much as shorter thiols, within the time-scale of the test. On each copper strip, there is a layer of copper oxide upon which regions of hydrocarbon or thiolate may form. For larger thiols, there is less thiolate coverage of regions of copper oxides than there is for shorter thiols, but there is less oxygen detected than for a polished copper strip because there is still some coverage of the regions of oxide.

Table 3 shows that cyclohexanethiol and 1-hexanethiol are similar in reactivity. However, when compared with thiophenol, it is clear that the aromatic thiophenol is more reactive than either the aliphatic or the cyclic thiols. The increased reactivity of the aromatic thiols is probably due to the interaction of the delocalized $\pi$ electrons with the copper surface.

The results in Table 3 show that of the sulfides and disulfides tested at $20 \mathrm{mg} \mathrm{S} / 1$ [S], diphenyl disulfide was the only species to react with the copper strips. However, the concentration of sulfur detected at the surface after the ASTM D130 test in iso-octane and diphenyl disulfide was only $1 \%$. The depth profile shown in Figure 4 confirms that the sulfur-containing surface film formed in this test was in fact very thin: after one and a half minutes of sputtering, the film had disappeared. This suggests that the surface film was in the order of a monolayer, consistent with the presence of diphenyl disulfide molecules oriented horizontally on the 
surface and most likely bonded through the sulfur and through interaction of the $\pi$-orbitals of the aromatic rings with the surface. Oxygen was still present after the majority of the hydrocarbon and sulfur layer has been sputtered away. This is consistent with the diphenyl disulfide molecules forming a monolayer on top of a copper oxide layer.

\subsection{Surface Concentration vs. Solution Concentration of Individual}

\section{Compounds: elemental sulfur, ethanethiol and thiophenol.}

The ratings from all the ASTM D130 corrosion tests on individual sulfur compounds vs. concentration are summarised in Table 4. The results show that the only ratings that could be obtained from a solution containing elemental sulfur and iso-octane were ' $1 \mathrm{a}$ ' and ' $4 \mathrm{a}$ '. At 5 $\mathrm{mg} / \mathrm{l}$ elemental sulfur, the rating was ' $1 \mathrm{a}$ '. At $50 \mathrm{mg} / \mathrm{l}$ and above, the rating was ' $4 \mathrm{a}$ ', but it was difficult to assess the state of the strips tested in solutions of 10 and $20 \mathrm{mg} / \mathrm{l}$. On the copper strip tested in $20 \mathrm{mg} / \mathrm{l}$ elemental sulfur, it was just possible to discern a grey colour around the edges of the strip, causing the strip to be rated as ' $4 \mathrm{a}$ '. However, the strip tested in $10 \mathrm{mg} / \mathrm{l}$ elemental sulfur was borderline between ' $1 \mathrm{a}$ ' and ' $4 \mathrm{a}$ ', with the edges of the strip showing a faint discolouration that was only noticeable upon close inspection. Following the guidelines, this strip was rated as the higher of the two ratings in question.

In other measurements using $20 \mathrm{mg} / \mathrm{l}$ of elemental sulfur in iso-octane, ratings of $4 \mathrm{a}, 1 \mathrm{a}$ and $1 \mathrm{~b}$ were seen, illustrating the sensitivity of the test to the test conditions, and the subjective nature of the result.

Surface concentrations of sulfur on the test surfaces after testing in iso-octane with elemental S, ethanethiol or thiophenol, as measured by XPS, are shown plotted in Figure 5 against test solution concentration (sulfur equivalent) up to $50 \mathrm{mg} \mathrm{S} / \mathrm{l}$. The elemental sulfur results show an approximately monotonic increase of surface sulfur concentration with the test solution 
concentration whereas the ethanethiol and thiophenol appear to show more rapid initial rises followed by plateaux.

Extension to much higher concentrations of elemental $\mathrm{S}$ in iso-octane was found to result in growth of a thick dark grey / black film material that readily peeled away from the surface. A powder X-ray diffraction (XRD) measurement from a typical sample of this material showed a number of relatively broad peaks on a low background, indicating a high degree of crystallinity but with a small average crystallite size. Main peaks were attributable to $\mathrm{Cu}_{1.75} \mathrm{~S}$, with some overlap with $\mathrm{Cu}_{2} \mathrm{~S}$. A substantial minor contribution from $\mathrm{Cu}_{1.8} \mathrm{~S}$ was also present. $\mathrm{Cu}_{2} \mathrm{O}$ was also identified, with sharper peaks and therefore a likely larger crystallite size, and there was some evidence for a low level of $\mathrm{CuO}$. All phases identified were of cubic symmetry, with the exception of the low-level monoclinic $\mathrm{CuO}$, and all sulfur compounds were monosulfides.

Inspection of the high resolution XPS $2 p$ spectra from all concentrations of elemental sulfur up to $50 \mathrm{mg} / \mathrm{l}[\mathrm{S}]$ indicated $\mathrm{Cu}-\mathrm{S}$ bonds in all cases. The $\mathrm{Cu} 2 \mathrm{p}_{3 / 2}$ peaks were consistent with $\mathrm{Cu}(\mathrm{I})$ or metallic $\mathrm{Cu}$, and there was no evidence for $\mathrm{C}-\mathrm{S}$ bonding in the carbon peaks. Following initial $\mathrm{S}$ adsorption and $\mathrm{Cu}-\mathrm{S}$ bond formation at the surface, it is likely that further copper sulfide growth occurs via diffusion of $\mathrm{Cu}$ from the underlying metal through defects in the $\mathrm{Cu}-\mathrm{S}$ film to the surface, producing a macroscopic $\mathrm{Cu}_{2} \mathrm{~S}$ film. With time, the film therefore continues to grow and thicken, eventually becoming physically unstable and spalling away from the substrate. The ASTM D-130 / ISO 2160 test is carried out for a fixed time, therefore the thicker film growth is only seen at the higher sulfur concentrations. Longer test times may be expected to result in similar effects at lower elemental sulfur concentrations. Results of testing copper strips in iso-octane containing increasing amounts of ethanethiol are included in Figure 5. The only solution to fail the ASTM D130 test in this case was the one 
consisting of iso-octane and $50 \mathrm{mg} \mathrm{S} / 1$ ethanethiol, with a rating of ' $2 \mathrm{a}$ '. The strip tested in 20 mg S/l ethanethiol was rated a ' $1 \mathrm{~b}$ ' and the remainder were rated ' $1 \mathrm{a}$ '.

For ethanethiol, the surface concentration of sulfur initially rose rapidly with increasing test solution concentration, and then beyond $5 \mathrm{mg} / \mathrm{l}[\mathrm{S}]$ rose only slowly to a value of approximately 22 atom \% surface concentration. Inspection of the XPS peak-shapes and binding energies indicated this initial thin layer to comprise of mainly copper (I) sulfide.

Even at very low concentrations of ethanethiol in the test solution, there was a high concentration of sulfur at the surface. The strip tested in $5 \mathrm{mg} \mathrm{S} / 1$ ethanethiol (rated ' $1 \mathrm{a}$ ') had almost the same surface composition as the strip tested in the failing solution of $50 \mathrm{mg} \mathrm{S} / \mathrm{l}$ ethanethiol (rated '2a'). This shows that even when the same sulfur species is present in solution and forms surface films of almost the same composition on the copper strips, one solution can pass the ASTM D130 test whilst another can fail. There is evidence to suggest that strips rated as ' $1 \mathrm{a}$ ' to ' $3 \mathrm{a}$ ' are different only in film thickness (Kashima and Nose, 1959) and the different appearances may arise from interference effects dependent upon film thickness.

Inspection of the spectra showed that at all concentrations the $S 2 p$ photoelectron peaks were between the values expected for $\mathrm{Cu}-\mathrm{S}$ and $\mathrm{C}-\mathrm{S}$, indicating that at least some of the sulfur atoms at the surface were still bonded to the hydrocarbon chains. From Figure 5, it appeared that $5-10 \mathrm{mg} \mathrm{S} / \mathrm{l}[\mathrm{S}]$ ethanethiol was sufficient to form a stable layer on the test strip surface during the test, with higher concentrations resulting in only a gradual increase in surface $S$ concentration and a corresponding gradual decrease in surface $\mathrm{O}$ concentration. This suggests initial adsorption of ethanethiol on relatively cleaner areas of the test strip followed by gradual reduction and displacement of the residual surface oxide, in agreement with the results of Sung et. al (2000) and Fonder et. al.(2008) on oxidised polycrystalline copper surfaces . 
Overall, the results indicate the presence of a very thin thiolate film at the surface with copper (I) sulfide underneath, as a result of the diffusion of sulfur atoms into the copper.

Figure 5 also shows the surface sulfur composition of a series of copper strips tested in isooctane with increasing concentrations of thiophenol (benzenethiol). The trends are similar to those seen for ethanethiol, although the overall levels of surface $\mathrm{S}$ were intermediate between those found for the tests with ethanethiol and with elemental sulfur. A low concentration of thiophenol was sufficient to cause a large increase in sulfur concentration at the surface and as for ethanethiol there was little difference in relative concentrations of elements between the strip tested in a solution of $10 \mathrm{mg} \mathrm{S} / 1$ thiophenol and the strip tested in a solution of $50 \mathrm{mg} \mathrm{S} / \mathrm{l}$ thiophenol. However, unlike ethanethiol, all of the strips tested in iso-octane and thiophenol were rated as ' $1 \mathrm{a}$ ' and the ratio of carbon to sulfur in the surface films was much higher due to the greater number of carbon atoms per molecule of thiol.

High resolution S 2p and C 1s spectra from the $10 \mathrm{mg}$ S/l sample are shown in Figure 6, and are typical of all such spectra from this series of tests. The principle component of the $\mathrm{C} 1 \mathrm{~s}$ peak is due to $\mathrm{C}-\mathrm{C}$ bonds in hydrocarbon. Smaller contributions from a range of oxygen bonding types are seen, typical of those found from the interactions of hydrocarbon species with surface oxide. Also seen is a rather weak feature at higher binding energy that is attributed to a shake-up transition involving $\pi$ orbitals of the aromatic ring. This shake-up feature is at a slightly lower binding energy than would be expected from the isolated molecule, probably as a result of orientation of the aromatic ring parallel to the surface and the consequent interaction of the $\pi$ orbitals with the underlying metal and oxide. A contribution to the $\mathrm{C}$ 1s peak from the C-S bond in thiophenol is expected, as the thiophenol molecule is unlikely to dissociate at the surface. However, such a component is not seen. Reference data indicate expected chemical shifts of $\sim 0.5 \mathrm{eV}$ for $\mathrm{C}-\mathrm{S}$ bonds where the carbon is in an aliphatic configuration, but only $\sim 0.2 \mathrm{eV}$ where the $\mathrm{S}$ is bonded to an aromatic ring (Beamson 
and Briggs, 1992). Such a small shift would not be resolved in spectra from non-ideal samples showing a range of chemical bonding states, as examined here.

The sulfur $2 \mathrm{p}$ spectrum shows a well-resolved $2 \mathrm{p}_{3 / 2-1 / 2}$ doublet at a binding energy intermediate between values expected for bonding to copper as a sulfide and bonding to an aromatic ring. There is also a weak contribution centred at approximately $168 \mathrm{eV}$ binding energy in which the doublet is not resolved. This corresponds to a low level of sulfur being present in an oxidized form, probably due to either dissolved air in the iso-octane, or air exposure during transfer between the test fluid and the vacuum of the XPS instrument.

\subsection{Elemental Sulfur and Thiol compounds in combination, at $20 \mathrm{mg} / \mathrm{l}[\mathrm{S}]$}

Rating results for combinations of elemental sulphur and thiol compounds are summarised in Table 5 and surface concentrations of $\mathrm{S}$ on copper strips tested using iso-octane solutions containing elemental sulfur and a thiol blended to maintain $20 \mathrm{mg} / \mathrm{l}[\mathrm{S}]$ are shown in Figure 7. At $0 \%$ thiol (i.e. $20 \mathrm{mg} / \mathrm{l}$ elemental $\mathrm{S}$ ) the results agree with the results shown in Figure 5 for this concentration. However, as the proportion of thiol was increased, the surface concentration of $S$ also increased up to a value of $20-25 \%$ at a point where $25 \%$ of the $S$ in the test solution was present as a thiol. Beyond this, the concentration continued to rise slightly in the case of ethanethiol, levelled off in the case of propanethiol, and dropped in the case of thiophenol. In all three cases, a reduction in surface sulfur concentration was seen as the thiol concentration in iso-octane became sufficient to account for most or all of the 20 $\mathrm{mg} / \mathrm{l}$ total S. At $100 \%(20 \mathrm{mg} / \mathrm{l})$ the surface compositions agreed with those measured when copper strips were tested with the thiols alone at these concentrations. Between the two extremes, it appears that mixing the two components causes a synergistic effect in the test resulting in higher concentrations of surface $S$ than would be achieved by either component separately. 
In the case of ethanethiol it was noted that in the central region of the plot, the ratios of carbon to sulfur and copper to sulfur were both less than two to one, indicating that the sulfur could not be just bonded to the hydrocarbon. From the spectra used to produce Figure 7, it appeared that the copper was either in the $\mathrm{Cu}$ or the $\mathrm{Cu}^{+}$state and the sulfur at the surface of the samples was a mixture of copper ethanethiolate $\left(-\mathrm{Cu}-\mathrm{S}-\mathrm{C}_{2} \mathrm{H}_{5}\right)$ and $\mathrm{Cu}_{2} \mathrm{~S}$. As expected, when the ethanethiol was the only sulfur species in the test solution, the ratio of carbon to sulfur was at least two to one. Similarly, when propanethiol was used, the results indicated a mix of $\mathrm{Cu}_{2} \mathrm{~S}$ and copper 1-propanethiolate at the surfaces, and when thiophenol was used the ratio of carbon to sulfur on the strip's surface matched the carbon to sulfur ratio in thiophenol, suggesting that at least the outermost part of the surface film was copper benzenethiolate.

The appearance of the strips tested with elemental sulphur and ethane thiol varied greatly but the ratings did not, with this series of experiments only producing strips with ratings of ' $1 \mathrm{~b}$ ' or '4a'. Iso-octane and ethanethiol alone produced a strip of rating ' $1 \mathrm{~b}$ ', yet the synergistic effect observed between the elemental sulfur and the ethanethiol produced strips of only ' $4 \mathrm{a}$ ', as a dark grey colour was visible on all other strips.

The strips produced with elemental sulfur and propanethiol had a similar appearance to those that were tested in ethanethiol and elemental sulfur, with the thiol on its own producing a strip that passed the test (with a rating of ' $1 \mathrm{a}$ '), as expected. The solution of $15 \mathrm{mg}$ S/1 1propanethiol with $5 \mathrm{mg} / \mathrm{l}$ elemental sulfur produced a rating of ' $1 \mathrm{~b}$ '. As with ethanethiol and elemental sulfur, the strip rated as ' $1 b$ ' had several times more sulfur than the strip tested in iso-octane and elemental sulfur alone (which was rated '4a'). The other two strips were also rated as ' $4 \mathrm{a}$ ' due to the presence of areas of grey.

The strips tested in solutions containing elemental sulfur alone (rated '4a'), thiophenol alone (rated '1a') and a mixture of thiophenol and elemental sulfur in a ratio of 3:1 (rated ' $1 \mathrm{~b}$ ') all appeared similar to their equivalents where 1-propanethiol was used. The strip tested in iso- 
octane with thiophenol and elemental sulfur in a ratio of 1:3 was rated as ' $3 b$ '. However, the silver colour visible on much of the surface made it more difficult to rate, because if the silver colour were interpreted as grey then the strip would have been rated ' $4 a$ '. The other strip (with a thiophenol to elemental sulfur ratio of 1:1) was even more difficult to rate, due to its yellowish green appearance that was not represented anywhere on the corrosion standard or in the descriptions of the ratings. On consideration, this strip was rated a ' $3 b$ ' because of its multicoloured appearance and the guidance that when strips appear to be somewhere in between two ratings, they should be rated as the higher of the two.

The strip that was rated '4a' (with elemental sulfur alone in iso-octane) had less than a quarter of the concentration of sulfur at the surface as the strip rated '1b'. Again, ratings were found to be neither proportional to the concentration of sulfur on the surface of test strips nor to the concentration of sulfur in test solutions.

\subsection{Diphenyl Disulfide and propanethiol at $20 \mathrm{mg} / \mathrm{l}[\mathrm{S}]$}

The results of using diphenyl disulphide and propanethiol in combination in iso-octane at a constant total sulfur concentration of $20 \mathrm{mg} / \mathrm{l}[\mathrm{S}]$ are shown in Figure 8. All tests in this series were rated at ' $1 \mathrm{a}$ ' (Table 5). With $0 \%$ propanethiol (100\% diphenyl disulphide) the surface sulfur concentration is low, in agreement with the results in Table 3. Similarly, the result at $100 \%$ propanethiol was also in agreement with results in Table 3. At intermediate concentrations, the surface concentrations remained close to the value for $100 \%$ propanethiol, suggesting that diphenyl disulphide did not act as an effective inhibitor for the formation of propanethiol surface films. That is, the diphenyl disulphide, even at near $20 \mathrm{mg} / \mathrm{l}[\mathrm{S}]$ concentrations, formed only a partial layer on the surface during the time of the test, leaving many vacant sites at the surface which were filled when exposed to even low concentrations of propanethiol. 


\subsection{Diphenyl disulphide added to $20 \mathrm{mg} / \mathrm{l}$ [S] of either elemental $\mathrm{S}$ or}

\section{propanethiol}

Figure 9 shows the results of testing in iso-octane to which increasing amounts of $S$ in the form of diphenyl disulphide have been added to solutions containing $20 \mathrm{mg} / \mathrm{l}$ [S] as either elemental $\mathrm{S}$ or as propanethiol. Ratings for this series of tests are given in Table 6. Addition of diphenyl disulphide at concentrations of up to $500 \mathrm{mg} / \mathrm{l}[\mathrm{S}]$ to the solution of $20 \mathrm{mg} / \mathrm{l}$ [S] as propanethiol resulted in only a small increase of the sulfur level on the test surfaces from $15 \%$ (no diphenyl disulfide added) up to $\sim 17 \%$ (500 mg/l [S] diphenyl disulfide). This suggests the propanethiol layer nearly saturated the surface, leaving only a small number of vacant sites suitable for the diphenyl disulphide to bond to, and which were gradually filled as the concentration of diphenyl disulphide in solution was increased.

The opposite trend was seen in the case where tests were conducted after adding diphenyl disulfide to the test solutions containing $20 \mathrm{mg} / \mathrm{l}[\mathrm{S}]$ as elemental sulfur. Here the initial surface concentration of sulfur of $\sim 22$ atom $\%$ was reduced to $\sim 11$ atom $\%$ by the addition of $200 \mathrm{mg} / \mathrm{l}[\mathrm{S}]$ as diphenyl disulhide, and this then remained approximately constant up to the final addition to $500 \mathrm{mg} / \mathrm{l}[\mathrm{S}]$. Here it appears that the presence of the diphenyl disulfide in solution either results in competition for surface sites with the elemental $\mathrm{S}$, or reduces the amount of elemental $S$ available for bonding to the surface within the test time as a consequence of an interaction in solution.

The key factors here are the reactivity of the two species with the copper test strip and the size of the two molecules. Although the larger diphenyl disulfide molecule may be able to occupy a larger area of the copper strip (inhibiting further reaction) than a 1-propanethiol molecule can, once the surface is partially covered, the rate of adsorption of diphenyl disulfide will drop significantly, due to the large surface area required. In contrast, the 1-propanethiol molecules 
bond through single carbon atoms with more dense packing than the diphenyl disulfide molecules. Thus, as the test proceeds, 1-propanethiol molecules will continue to form bonds with available copper atoms, whilst the unadsorbed diphenyl disulfide molecules will adsorb to the copper surface at a decreasing rate, due to the diminishing area available for adsorption. All of the strips tested with elemental sulphur at $20 \mathrm{mg} / \mathrm{l}$ and diphenyl disulfide at a range of concentrations from $20 \mathrm{mg} \mathrm{S} / 1$ to $500 \mathrm{mg} \mathrm{S} / 1$ were 'fails' with various ratings. The darkest strip was rated a ' $4 \mathrm{a}$ ' due to a faint, uniform grey colour across the surface of the film. Despite the strip tested in $50 \mathrm{mg} \mathrm{S} / 1$ diphenyl disulfide being very similar in appearance to the strip rated as ' $4 a$ ', it was rated a ' $3 b$ ' because it did not have any visible grey across the strip. The strip tested at $100 \mathrm{mg} / \mathrm{l} \mathrm{S}$ diphenyl disulphide was also rated a ' $3 \mathrm{~b}$ ', despite featuring a large area of the same yellowish green colour that caused confusion when rating other strips. The strip tested in $200 \mathrm{mg} \mathrm{S} / 1$ diphenyl disulfide was rated a '2c' (silver on claret red), but it was not clear why this strip should not be rated a ' $2 \mathrm{~d}$ ' (silver), because the procedure for rating the strips states that when strips are between two ratings that they should be rated as the higher of the two. In this case, it seems that there should not be a ' $2 \mathrm{c}$ ' rating, as any strip featuring silver should be rated as a ' $2 \mathrm{~d}$ '. The rating of ' $2 \mathrm{c}$ ' does not correspond to any of the ratings described in Bolt's original work (Bolt, 1947) and was added later. Without this addition there would be an easy assessment of whether something was claret (' $2 \mathrm{a}$ '), lavender ('2b') or silver ('2d').

\section{Conclusions}

Surface analytical data and rating results have been presented from tests carried out under controlled laboratory conditions. Polishing the copper strips prior to the test significantly decreased the surface carbon concentration and caused a slight decrease in surface oxygen content. Testing a strip in iso-octane alone caused the strip to oxidize slightly during the 
duration of the test, probably due to the presence of dissolved air in the test solvent. The amount of carbon was equivalent to a film of average thickness approximately $2 \mathrm{~nm}$ thick, over a surface oxide layer approximately $1 \mathrm{~nm}$ thick. In practice, the film thickness will vary across the specimen surface, leaving areas of exposed oxide available for reaction with the sulfur species whereas other areas may have thicker layers of carbonaceous material present which must be displaced by any sulfur species in solution before bonding to the surface.

Copper strips tested in only iso-octane and elemental sulfur produce just two ratings: ' $1 \mathrm{a}$ ' and ' $4 \mathrm{a}$ ' and the concentration of elemental sulfur required for a failure was found to be in the region of $10 \mathrm{mg} / \mathrm{l}$. Of the sulfur species tested at $20 \mathrm{mg} \mathrm{S} / \mathrm{l}$, only elemental sulfur caused a test failure, with a rating of ' $4 \mathrm{a}$ '. Up until at least $100 \mathrm{mg} / \mathrm{l}$ elemental sulfur, the concentration of sulfur on copper test strips appeared to increase regularly with the concentration of elemental sulfur in the test solution. Eventually, reaction with sulfur in solution was found to produce a relatively thick, friable and unstable sulphide film, containing a mixture of $\mathrm{Cu}_{1.75} \mathrm{~S}$, $\mathrm{Cu}_{1.8} \mathrm{~S}$ and $\mathrm{Cu}_{2} \mathrm{~S}$ phases.

Solutions containing small amounts of thiols gave test strip surfaces more concentrated in sulfur than strips tested in a 'failing' solution of $i$ so-octane and elemental sulfur. Of the thiols tested individually, only ethanethiol yielded a 'fail', when at $50 \mathrm{mg} \mathrm{S} / 1$ a claret tinge made it a '2a' although it had a very similar surface composition to a strip rated as ' $1 \mathrm{a}$ ' after being tested in a solution containing just $5 \mathrm{mg} \mathrm{S} / \mathrm{l}$. The difference in appearance (and, therefore, in rating) was most likely due to difference in film thickness.(Kashima and Nose, 1959) The reactivity of thiols to copper within the time-scale of the test, as determined by their end-oftest surface concentration after testing using the same bulk sulfur concentration, was found to decrease with increasing carbon chain length. This was associated with steric hindrance by the carbon chain restricting access to the surface of thiol molecules in solution. The e surface chemical analyses indicate that strips tested in alkane thiols had an outermost layer of alkyl 
thiolate, with the possibility of some sulfur diffusing into the copper at higher concentrations and producing $\mathrm{Cu}_{2} \mathrm{~S}$ beneath.

When elemental sulfur was combined with a thiol in the test solution, the concentration of sulfur on test strips was higher than if the sulfur content of the test solution had been either entirely elemental sulfur or entirely thiol. For example, although neither $5 \mathrm{mg} / \mathrm{l}$ of elemental sulfur or $20 \mathrm{mg} \mathrm{S} / 1$ ethanethiol could separately fail the copper strip test, $2 \mathrm{mg} / \mathrm{l}$ of elemental sulfur with $18 \mathrm{mg} \mathrm{S} / 1$ ethanethiol together produced a failing rating of ' $4 \mathrm{a}$ '.

Thiophenol was found to be more reactive towards copper than either 1-hexanethiol or cyclohexanethiol. The tests combining thiophenol with elemental sulfur in solution showed that ratings were proportional to neither the concentration of sulfur in solution, nor the concentration of sulfur on the test strips. These effects were most likely due to interactions of the delocalized $\pi$ electrons of the aromatic ring with the copper surface. Diphenyl disulfide (at $20 \mathrm{mg} \mathrm{S} / \mathrm{l}$ ) in iso-octane was found to form only a monolayer on the copper test strip surface, also attributed to interactions of the $\pi$ electrons with the copper, along with bonding through $\mathrm{S}$ atoms. Under the conditions of the test, diphenyl disulfide appeared to have little effect on inhibiting the reaction between 1-propanethiol and copper, due to the reactivity of 1propanethiol and its molecular size. However, at high concentrations, diphenyl disulfide reduced the corrosion ratings (and the concentration of sulfur on the test strips) of strips tested in a solution of both diphenyl disulfide and elemental sulfur.

A corrosion test solution of $10 \mathrm{mg} \mathrm{S} / \mathrm{l}$ thiophenol with $10 \mathrm{mg} / \mathrm{l}$ elemental sulfur gave a copper strip a yellowish green appearance that did not feature anywhere in the ASTM / ISO corrosion standard or in the accompanying description of ratings. The closest match to an ASTM rating was a ' $3 b$ '. The description of a ' $2 c$ ' strip does not seem to add to the rating system, as a subjective judgement must be made as to when '... silver...overlaid on claret' becomes closer to being 'silvery'. This should be considered during any future revisions of the test 


\section{References}

Al Kharafi F.M., Abdullah A.M., Ghayad I.M. and Ateya B.G. (2007) 'Effect of Sulfide Pollution on the Stability of the Protective Film of Benzotriazole on Copper', Appl. Surf. Sci., 253: 8986-8991.

Bain C.D., Troughton E.B., Tao Y.-T., Evall J., Whitesides G.M. and Nuzzo R.G. (1989) 'Formation of monolayer films by the spontaneous assembly of organic thiols from solution onto gold' J. Am. Chem. Soc. 111: 321-335.

Beamson G. and Briggs D. (1992) 'High Resolution XPS of Organic Polymers: The Scienta ESCA300 Database', Wiley, Chichester.

Bolt J. A. (1947) ‘Copper-Strip Corrosion Tests’, Oil \& Gas J., 46: 99-100.

Clark P. D. and Lesage K. L. (2006) 'An Examination of Interfering Factors in the ASTM D1838 Copper Strip Test', GPA Research Project No. 982-2, The University of Calgary, Calgary, Alberta, Canada.

Ferral A., Patrito E.M. and Paredes-Olivera P. (2006) 'Structure and bonding of alkanethiols on $\mathrm{Cu}(111)$ and $\mathrm{Cu}(100)^{\prime}$, J. Phys. Chem. B 110: 17050 - 17062.

Feng Y., Teo W.-K., Siow K.-S., Gao Z., Tan K.-L.and. Hsieh A.K, (1997) 'Corrosion protection of copper by a self-assembled monolayer of alkanethiol', J. Electrochem. Soc., 144(1): 55-64.

Fonder G., Laffineur F., Delhalle J.and Mekhalif Z., (2008) “Alkanethiol-oxidised copper interface: The critical influence of concentration”, J. Coll. Interface Sci., 326: 333-338. García-Antón J., Monzó J. and Guiñón J. L. (1995) ‘Effect of Elemental Sulfur and Mercaptans on Copper Strip Corrosion and Use of the ASTM D 130 Test Method', Corrosion, 51(7): 558-566. 
García-Antón J., Monzó J., Guiñón J. L., Gómez D. and Costa J. (1990) ‘Study of Corrosion on Copper Strips by Petroleum Naphtha in the ASTM D-130 Test by means of Electronic Microscopy (SEM) and Energy Dispersive X-Ray (EDX)', Fresenius J. Anal. Chem., 337: 382-388.

ISO 2160:1998. 'Petroleum Products - Corrosiveness to copper - Copper strip test (ISO 2160:1998)', Brussels, European Committee for Standardization.

Kashima M. and Nose Y. (1959) 'An Electron Diffraction Investigation on the ASTM Copper Strip Corrosion Test', Bull. Japan. Petr. Inst., 1: 33-45.

Schreifels J. A., Bagwell T.and Weers J. J. (1989) 'Copper Corrosion Inhibition in Sour Hydrocarbon Fuels', Corrosion, Vol. 45(1): 84-91.

Schreifels J. A., Weers J. J.and Bagwell T. (1991) 'Time Dependent Formation of Sulfidic Films on Copper Substrates When Exposed to Hydrocarbons Containing Elemental Sulfur', Fuel Sci. \& Tech. Int., 9(10): 1223-1244.

Scofield, J.H. (1976) 'Hartree-Slater subshell photoionization cross-sections at 1254 and 1487 eV', J. Electron Spectrosc. Relat. Phenom., 8: 129-137.

Sung M.M., Sung K., Kim C.G., Lee S.S.and Kim Y. (2000) 'Self assembled monolayers of alkanethiols on copper surfaces', J. Phys. Chem. B 104: 2273-2277.

Tanuma S., Powell C.J. and Penn D.R. (1993) 'Calculations of Electron Inelastic Mean Free Paths. V. Data for 14 Organic Compounds over the 50 - 2000 eV Range', Surf. Interface Anal., 21: 165-176.

Vastag G., Szőcs E., Shaban A., Bertóti I., Popov-Pergal K.and Kálmán E. (2001)

'Adsorption and Corrosion Protection Behaviour of Thiazole Derivatives on Copper Surfaces', Solid State Ionics, 141-142: 87-91.

Ye X. R., Xin X. Q., Zhu J. J., and Xue Z. L. (1998) 'Coordination Compound Films of 1Phenyl-5-Mercaptotetrazole on Copper Surface', App. Surf. Sci., 135: 307-317. 


\begin{tabular}{|c|c|c|c|}
\cline { 2 - 4 } \multicolumn{1}{c|}{} & Rating & $\begin{array}{c}\text { Surface } \\
\text { Composition } \\
\text { (atom \%) S }\end{array}$ & $\begin{array}{c}\text { Binding energy } \\
\text { S 2 } \mathrm{p}_{3 / 2}(\mathrm{eV})\end{array}$ \\
\hline iso-octane & 1a & - & - \\
\hline + elemental sulfur & 4a & 3.7 & 162.23 \\
\hline + ethanethiol & $1 \mathrm{~b}$ & 18.4 & 162.53 \\
+ 1-propanethiol & 1a & 13.8 & 162.46 \\
+ 1-butanethiol & 1a & 6.2 & 162.47 \\
+ 1-hexanethiol & 1a & 3.2 & 162.62 \\
+ cyclohexanethiol & $1 \mathrm{a}$ & 2.9 & 162.65 \\
+ thiophenol & 1a & 8.4 & 162.82 \\
\hline + diethyl sulfide & 1a & - & - \\
+ diethyl disulfide & $1 \mathrm{a}$ & - & - \\
+ diphenyl sulfide & 1a & - & - \\
+ diphenyl disulfide & 1a & 1.0 & 162.69 \\
\hline
\end{tabular}

Table 1: Results from ASTM D130 test of iso-octane with individual sulfur species, blended to give $\sim 20 \mathrm{mg} / \mathrm{l}$ sulfur. 

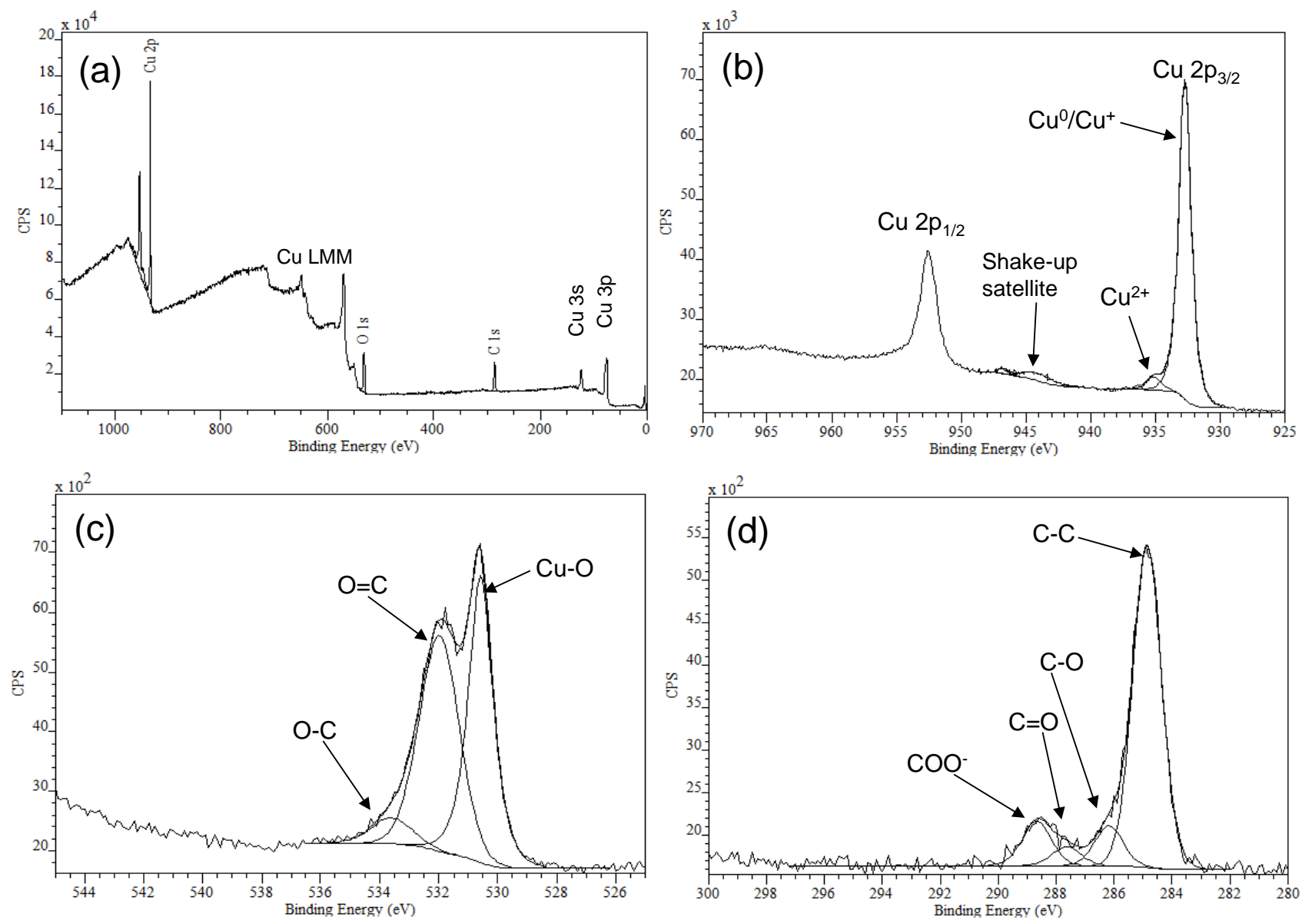

Figure 1: XPS data from the copper strip surface after polishing and testing in pure iso-octane according to the ASTM D-130 procedure. (a) Survey, (b) Cu 2p, (c) O 1s, (d) C 1s. 


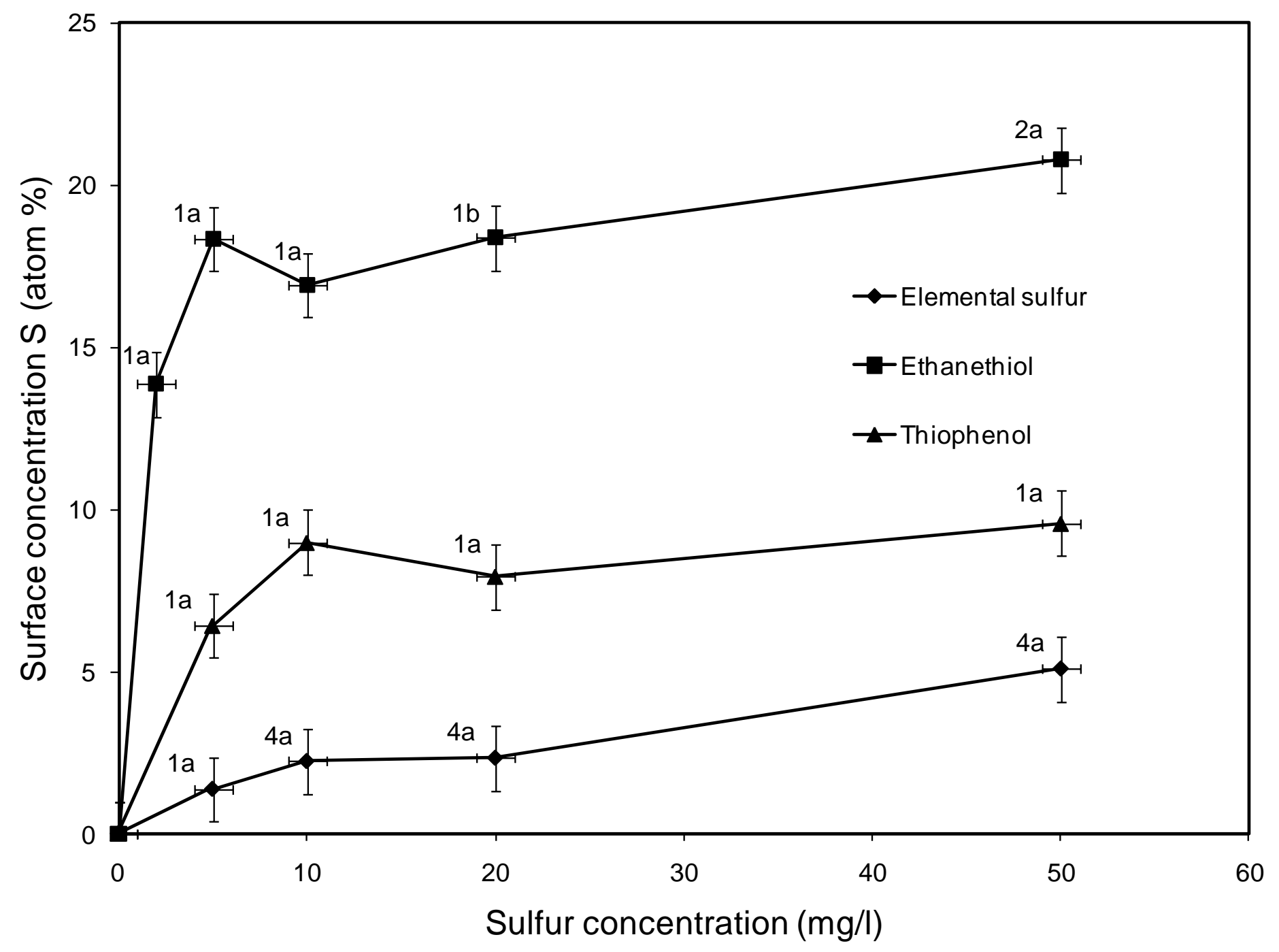

Figure 2: Sulfur composition of surface films formed after testing in iso-octane with either elemental sulfur, thiophenol or ethanethiol at solution compositions up to $50 \mathrm{mg} / \mathrm{l}[\mathrm{S}]$. The corresponding test ratings are indicated. 

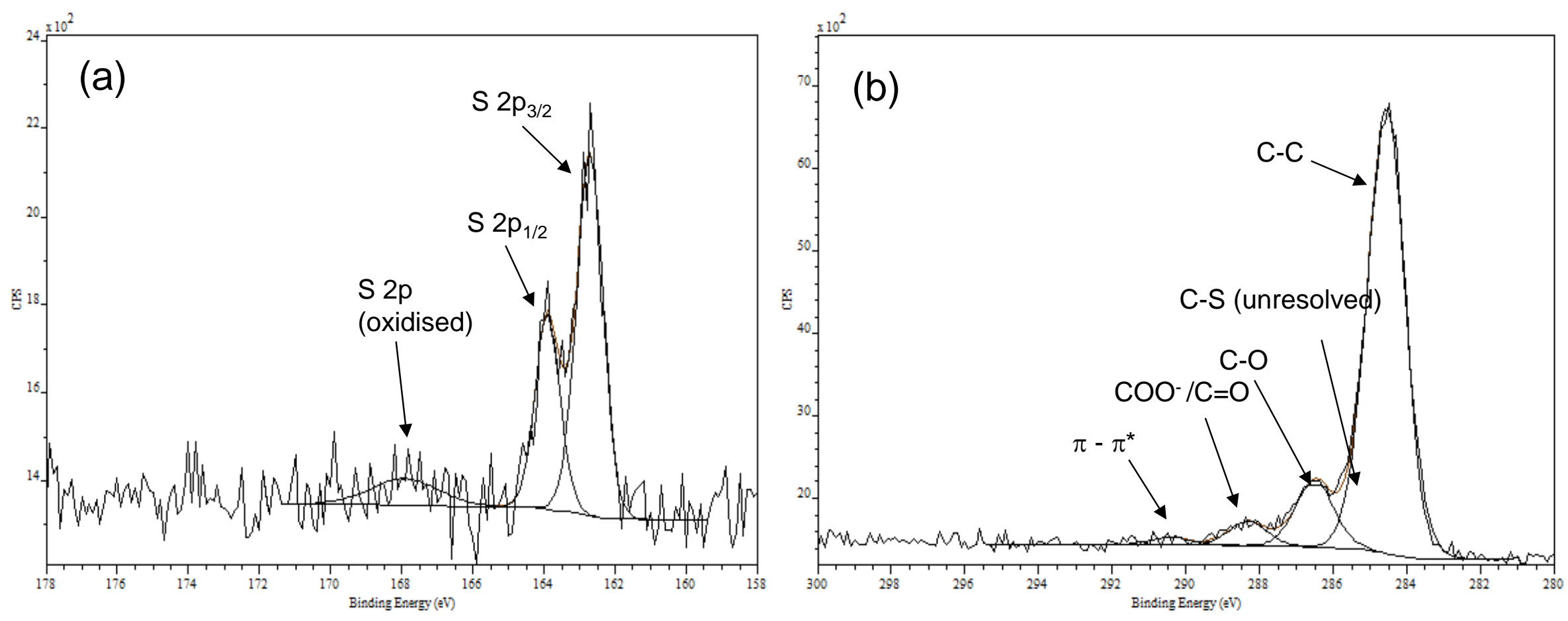

Figure 3: High resolution (a) S 2p and (b) C 1s spectra from the surface of the copper strip tested with 10 mg/l [S] thiophenol in iso-octane. 


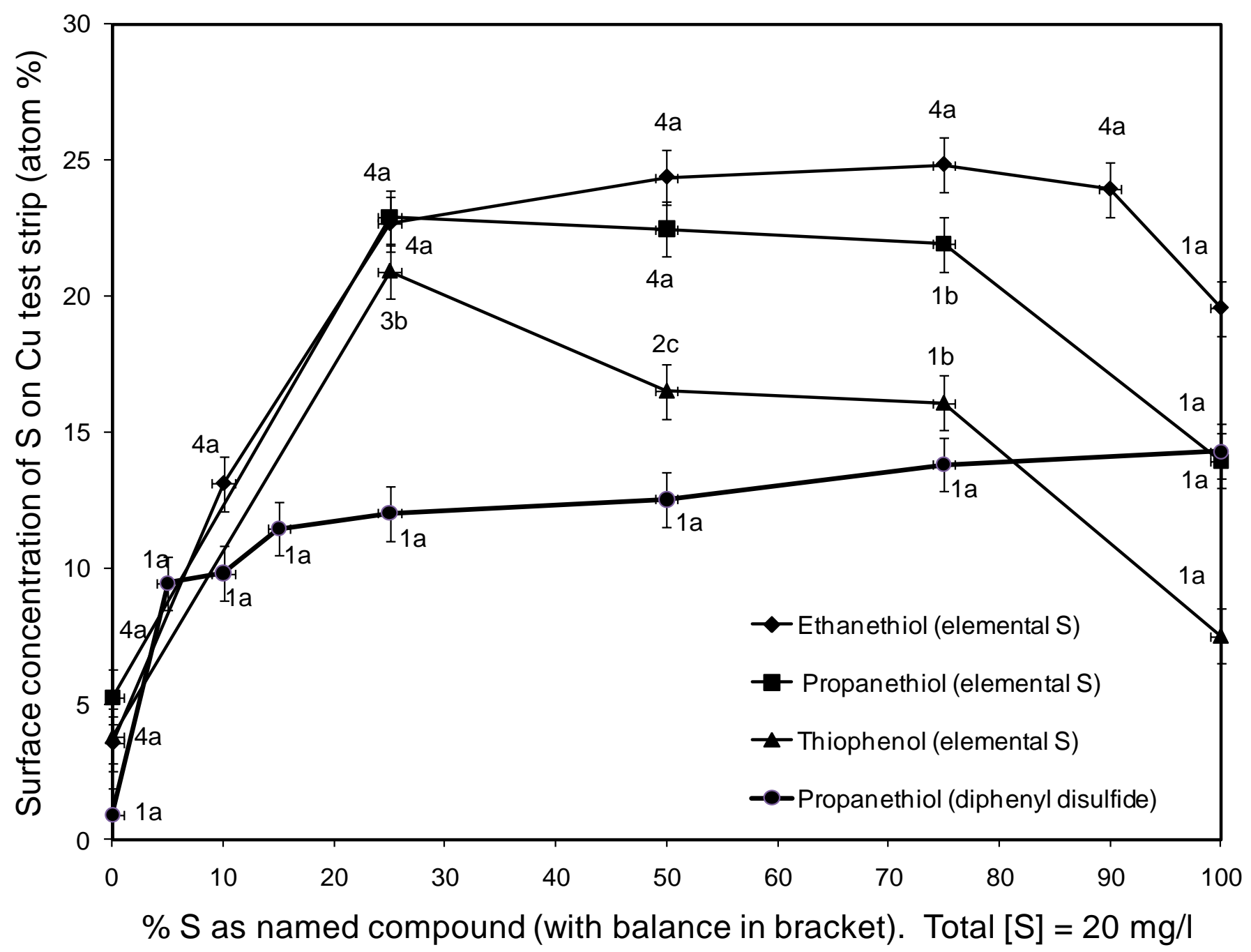

Figure 4: Concentration of sulfur in surface films formed on $\mathrm{Cu}$ strips tested in iso-octane with elemental sulfur in combination with ethanethiol, propanethiol or thiophenol, and with 1-propanethiol and diphenyl disulphide in combination. Total [S] $=20 \mathrm{mg} / \mathrm{l}$. 